\title{
A construção do protocolo de feridas como perspectiva de qualificação do cuidado na atenção primária à saúde: um relato de experiência
}

\author{
Nayara Rodrigues Carvalho, Marileila Marques Toledo, Érika Andrade Silva, Pauliana Pimentel \\ Coelho Garcia, Daniela Maria Comunian, Deíse Moura de Oliveira
}

\begin{abstract}
Resumo
A Atenção Primária à Saúde (APS) configura-se como o cenário de potência para colocar em prática os princípios doutrinários do Sistema Único de Saúde (SUS), sendo considerado o primeiro contato preferencial do usuário com o sistema e a coordenadora do cuidado nas Redes de Atenção à Saúde (RAS). A experiência de estudantes de enfermagem em uma unidade de saúde, no estágio supervisionado na APS, permitiu identificar que um dos cuidados mais cotidianos que cabe ao enfermeiro neste cenário é o tratamento de feridas, o qual comumente é realizado de modo não sistematizado, dificultando a integralidade da atenção aos portadores dessa afecção. Nesta perspectiva foi evidenciada a necessidade de construção de um protocolo assistencial voltado para o tratamento de lesões cutâneas dessa natureza, o que pode auxiliar os profissionais, em especial o enfermeiro, a prestar um cuidado pautado nos princípios do SUS. Relatar a experiência da elaboração do protocolo assistencial de Enfermagem para portadores de feridas assistidos na APS do município de Viçosa, MG. A construção do protocolo aconteceu no período de agosto a outubro de 2015, sendo composta por dois momentos. O primeiro momento aconteceu nos meses de agosto e setembro de 2015 e foi conduzido por duas estagiárias alocadas na unidade de saúde de um bairro periférico de Viçosa, juntamente com uma docente do curso de Enfermagem da Universidade Federal de Viçosa (UFV) e a gestora da APS do município. Nesta etapa procedeu-se a revisão da literatura sobre o tema, a fim de conferir um embasamento teórico e atual acerca do mesmo, o qual fundamentou a construção do material escrito. Foi também realizada a elaboração de instrumentos para coleta de dados, contemplando desde a anamnese à ficha de avaliação e evolução de feridas. A construção do protocolo contou ainda com a participação de enfermeiras da APS e do Centro de Atenção Secundária de Viçosa, as quais incentivarão junto aos seus pares o processo de implementação do protocolo, apresentado em outubro de 2015 pelas discentes de Enfermagem aos enfermeiros da APS. O desenvolvimento do protocolo assistencial no tratamento de feridas configurou-se como uma ação integradora e dotada de aprendizagem e crescimento para os discentes, docentes, enfermeiros e gestora da APS do município. A apresentação do protocolo aos enfermeiros fomentou um debate que deflagrou a despadronização e necessidade de atualização desses profissionais para o tratamento de feridas. Acredita-se que o protocolo, agregado ao interesse pessoal pelo aprimoramento, auxiliará na prestação de um cuidado qualificado, assegurando ao usuário menor tempo de tratamento e melhor assistência à saúde no âmbito do SUS. Cabe ressaltar que o protocolo está em tramitação no Conselho Regional de Enfermagem e na Prefeitura Municipal de Viçosa, para obtenção do respaldo por estes órgãos. Vislumbra-se que a construção do protocolo impactará na resolubilidade da APS e que, apesar dos desafios para a sua implementação, fortalecerá a comunicação entre os profissionais, bem como a construção da práxis no tratamento de feridas, impulsionando os envolvidos à prática da educação permanente.
\end{abstract}

Descritores: Cuidados de Enfermagem; Ferimentos e Lesões; Atenção Primária à Saúde. 